\title{
12 Uncertainty, fragmentation, and international obligations as shaping influences
}

\author{
Cyber security policy development \\ in Albania
}

\author{
Islam Jusufi
}

The debate around cyber security has become an area where national authorities seek to (re-)claim parts of their sovereignty in the name of national security. Therefore, cyber security has entered official state planning and policy processes, and departments are being established within national governance structures to deal with cyber security issues more authoritatively. Against this background, it is important to consider how states struggle to adapt to the challenges arising from cyberspace and which factors are particularly influential in shaping their policies. So far, little scholarly attention has been paid to small and medium-sized states that are transitioning toward becoming liberal democracies. This chapter attempts to fill part of this gap.

This chapter analyzes how uncertainties surrounding cyber security and international obligations are shaping cyber security policies in developing parts of the world, more specifically in Albania. On a general level, it shows that a governance regime in response to cyber security threats leads to a fragmentation of authority and a changed conception of how far state sovereignty can extend in cyberspace. Inversely, fragmented authority and accountability establish an open space for multi-actor approaches, leading to a pluralism of relevant actors. The state, this chapter shows, is nudged into sharing responsibilities with other actors, including the private sector, civil society, and individuals.

To make its point, this chapter assembles Albanian public discourses on technological uncertainties and multi-actorness. This is done by analyzing both important public Albanian documents for cyber security discussions and the more general Albanian discourse around cyber security. It will be shown that, with regard to cyber security, the national authorities of Albania have sought to protect different targets, including the state, the private sector, and civil society, which have not been historically or consistently central to the Albanian conception of sovereignty. The main influence, it seems, is international collaborations with NATO and the EU, in which cyber security matters are embedded.

The chapter is organized in three sections. In the first, the chapter reviews literature about how states face cyberspace in general. Section two sets out the cyber 
security policies designed and implemented in Albania, particularly as regards the three important aspects of uncertainty, fragmentation of authority, and international obligations. The third section draws conclusions.

\section{States struggle with sovereignty rights in cyberspace: A general view}

When it dawned on states that cyberspace was becoming an important aspect of international politics, they initially attempted to assert their sovereignty, traditionally understood as a right exclusive to states and particularly important in the face of national security matters. However, three aspects of cyberspace constrained state actors' coercive behavior in this regard: Uncertainty posed by technology, the presence of many non-state actors staking out their own claims, and, most importantly, international obligations.

\section{Uncertainties arising from cyber technologies}

Cyberspace, unlike the air, the space, or the sea, is an entirely man-made realm (Deibert et al. 2008) and as such subject to extensive uncertainties and unpredictability. Thus, a central and longstanding problematic in the practice of cyber security has become the inability to foresee, identify, and act upon threats in time (Dunn Cavelty 2019). The issue of uncertainty is thus an intrinsic part of cyber security, since uncertain threats need to be considered, prepared for, and dealt with continuously by someone who has the capacity to do so.

In addition, societies around the world are growing increasingly dependent on critical infrastructure networks, and risks to critical infrastructure systems are therefore seen as threats to the entire system of modern life and being. There is no place that is safe from an attack; a potential yet imminent threat is now perceived as coming from everywhere, which feeds a permanent sense of vulnerability and inevitable disaster (Dunn Cavelty 2013). Uncertainty about the capabilities and intentions of others also drives a classic security dilemma, boosting incentives for states to build up offensive and defensive cyber capabilities (Dunn Cavelty and Wenger 2020).

A prime issue for law enforcement against cyber threats in this uncertain environment is the "attribution problem", which refers to the difficulty of clearly identifying those responsible for a cyberattack (Dunn Cavelty 2008; Egloff 2019; Dunn Cavelty and Wenger 2020). Also, public attribution of cyber incidents takes place in a heavily contested information environment where multiple truths continue to coexist (Egloff 2019). Despite the expectation that attributional uncertainty may lead to the blame being placed on old enemies more often than not (Schulzke 2018), different actors in this contested environment gain authority to frame the aggressor behind cyber incidents, leading to a fragmentation of authority when it comes to attribution and other important aspects of cyber security. 


\section{Islam Jusufi}

\section{Fragmentation of authority}

The functioning of the Internet is heavily reliant on governance arrangements comprising both state and non-state actors. Many studies have established that the state is just one important player among others, which leads to the inability of states or transnational security organizations to enforce preferred cyber outcomes unilaterally. De facto control over the internet's technical components and the data flowing through them is exercised by private actors. States are adapting to this networked and fragmented governance more or less enthusiastically by attempting to shape standards and practices in a multi-stakeholder environment (Mueller et al. 2013). The use of alternative means to regulate cyberspace has allowed the interference of non-state actors at the expense of state institutions, and this undermines the power of the state in cyberspace (Adams and Albakajai 2016; Gendron 2013), which manifests in most states' inability to control flows of information, capital, and services across cyberspace.

In their efforts to regulate the use of cyberspace within their own borders, states have enacted multiple legislations and instituted new structures and actors (Betz and Stevens 2011). Fundamentally, it has become apparent that states cannot assure the security of information systems alone; instead, responsibility for information security needs to be dispersed across all stakeholders, because the majority of cyberspace is owned and operated by private companies (Bronk 2008). Thus, states will often need to request that private actors operating in their territories take the necessary actions to prevent or terminate detrimental international cyber conduct.

Nevertheless, the state occupies the central role in mobilizing and coordinating responses to the threats caused by cyber security. There is both a symbolic and a practical aspect to this: The role played by the state in responding to actual cyber threats is central in alleviating insecurities. When such threats emerge and are contained within the jurisdiction of a single territory, then the state exercises its traditional role of safeguarding the well-being of its citizens (Thomas 2009). This regards the reproduction of the state as political sovereign and holder of the monopoly of violence (Dunn Cavelty and Jaeger 2015). But, to address cyber threats in a comprehensive manner, states must also cooperate with other stakeholders to achieve mutually beneficial outcomes. Such collaboration implies a degree of policy constraint that goes against the ideal of absolute state sovereignty.

Like many other complex policy issues, cyber security cuts across different areas of responsibility, requiring coordination and cooperation between a wide variety of public actors at different levels of government as well as actors from business and society (Dunn Cavelty and Wenger 2020). In this multi-actor environment, the more the issue is presented as concerning all angles of society, the more natural it seems that the keeper of the peace in cyberspace should be multiple actors (Dunn Cavelty 2014). Thus, governments are embracing a growing "multi-actorsovereignty" movement to respond to the uncertainties of cyberspace. The different roles of different actors are politically contested, though. Furthermore, states face a series of additional pressures, for example from international obligations. 


\section{International obligations}

Changes to the understanding of "sovereignty" are common these days. States can sign conventions in which a degree of sovereignty is surrendered in the common interest. The Council of Europe's 2001 Convention on Cybercrime, also known as the Budapest Convention, is a good example of how states have come together to tackle a transnational problem while voluntarily allowing for changes in internal legal frameworks and an increase in cross-border investigative actions (Betz and Stevens 2011; Council of Europe 2001). The cyber security regulations of the EU and NATO, which impose obligations on existing and aspiring member states, are generally considered to constitute a baseline legislative framework for nations seeking to address cybercrime. Thus, international obligations have accelerated the process of embracing the conception of "multi-actor-sovereignty". In the next section, it will be shown how this plays out in the case of Albania.

\section{Albania develops cyber security policies}

The development of cyber security policy in the Southeast European country of Albania is very recent. Nevertheless, Albania is increasingly becoming a technology service economy and as such depends more and more on its information infrastructure to run its businesses on a daily basis. This level of reliance on information infrastructure has led to the perception of vulnerabilities (Brechbühl et al. 2010), especially as instances of network and information security breaches are growing rapidly, highlighting the need for action (McAfee 2012).

Albania has increasingly become both the origin and target of cyberattacks, with the first recorded case of cybercrime in 2008. The number of cybercrimes uncovered by police in recent years has grown steadily, with hacking, phishing scams, credit card number theft, identity theft, and malware such as Trojans, which enable criminals to take remote control over thousands of computers, being among the most prevalent crime types. Albania is constantly moving up in the list of countries where users are targeted by harmful software (Arka Telecom 2018). These new security threats challenge Albania's protective capabilities and have put cyber security firmly on the Albanian national agenda. As threats in cyberspace have become abundant, there is rising pressure to take action.

In order to respond to its growing cyber security challenges, Albania has taken steps to enhance both its domestic cyber security capacity and its international cyber security cooperation and partnerships (Begaj 2014). The country's size, combined with its location at the European periphery, has driven Albania to pay attention to strategic alliances and institutional cooperation. Also, the understanding of the term cyber security in Albania has changed over time. Initially, it was understood primarily as a technical risk management issue in critical information infrastructure protection, but it has come to be understood as a key challenge of national security (cf. Dunn Cavelty and Egloff 2019). The three issues outlined above, i.e. technological uncertainties, the fragmentation of authority, and international obligations, all shape Albania's approach to cyber security. 


\section{Technological uncertainty and the role of non-state actors as understood in Albanian public discourse}

Albania's strategic doctrinal framework regarding cyber security consists of a series of documents, including, among others, the Law on Cyber Security, the Cross-Cutting Strategy "Digital Agenda of Albania 2015-2020", the CrossCutting Strategy on the Information Society 2008-2013, the Policy Paper on Cyber Security 2015-2017, the National Security Strategy 2014-2020, the Cyber Defense Strategy 2018-2020, and the Cyber Defense Strategy 2014-2017 (Republic of Albania 2014a, 2014b, 2015a, 2015b, 2017, 2018a, 2018b).

Albania's core cyber security provisions are established by its 2017 Law on Cyber Security (Republic of Albania 2017). When reading important provisions of that law, one finds that uncertainty is a guiding logic for the country's view on how to respond to cyber security incidents. The law defines cyberspace as a "digital environment capable of creating, processing and exchanging information generated by systems" (Article 3, 2017 Law on Cyber Security) and acknowledges that other actors besides the state, such as private legal persons, also have a role to play in cyber security governance, including the "private sector, which administers critical information infrastructure" (Article 3, 2017 Law on Cyber Security).

Another important strategic document is the Cross-Cutting Strategy "Digital Agenda of Albania 2015-2020". It aims to enhance Albania's resilience across sectors against cybercrime, cyber espionage, hacktivism, and terrorist use of the internet. It is an inter-sectoral strategy that establishes public-private collaboration and partnership as well as inter-sectoral, local-central, regional, and international collaboration as part of the basic principles for the development of the digital agenda (Dushi 2016). It is a document with which Albania plans, in a systematic and comprehensive way, the most important activities for protecting all users of modern electronic services, both in the public and economic sectors and among the general population (Bahiti and Josifi 2015). The aim of the Strategy is to achieve a balanced and coordinated response to the security threats of modernday cyberspace by various institutions representing all sectors of society.

The Strategy is a statement of the cyber security stakeholders' determination to take measures in their respective areas of responsibility, to cooperate with the other stakeholders, and to exchange the necessary information (Galinec et al. 2017). For the Strategy, the internet is a vehicle to "integrate ... public administration and private sector services" (p. 9). The Strategy itself commits the government to "cooperate ... with businesses, universities, non-profitable organizations and NGOs in Albania, for an efficient development of the information society in the country" ( $p$. 25). For the Strategy, the development of an internet society in Albania

constitutes a joint objective of all actors, such as the public sector, the academic world, NGOs, civil society and private organizations. The successful completion of this objective is related to the proper coordination and harmonization of developments among all sectors and actors. 
The earlier national strategy was the Cross-Cutting Strategy on the Information Society 2008-2013. Uncertainty was also among the assumptions underlying that strategy: "With the fast-developing information technology and its expansion into almost all areas of activity of society, the need for secure and reliable services becomes ever more obvious" (p. 36). The strategy was also committed to cooperation with different actors, including "other national and international institutions, civil society and the private sector in the Information Society realm" (p. 36), and it stated that the state administration will "cooperate with civil society and private bodies" (p. 39).

Another important public document has been the Policy Paper on Cyber Security (2015-2017), which aims to coordinate the duties and responsibilities of all actors involved in maintaining a secure cyberspace. One of the strategic objectives of this document is the strengthening of partnerships with various responsible stakeholders. This policy paper describes in more detail the fields of collaboration with different stakeholders, such as strengthening the collaboration with internet service providers as regards the treatment of cyber incidents and measures for blocking access to websites with illegal content; collaboration with civil society regarding the online safety of children; collaboration with academia on the opening of specialized study programs about cyber security; and collaboration with the banking sector, which, according to this document, should be represented in any legal or technical initiative taken in the field of cyber security. For this policy paper, the uncertainty of the technology has again been a main assumption: "The fast development of Information and Communications Technology and the extent of its use in almost all areas of activity of society have highlighted the need for safe and reliable services" (p. 8). The uncertainty assumption can also be found in the following sentence of the policy paper: "Developing cyber security under the circumstances of an information technology that is changing daily demands particular attention from the public institutions" (p. 29).

For this policy paper, the private sector is accepted as a referent object besides the state: "The increase in the use of communication represents an added value for the economic and social development of the country, but at the same time it makes it vulnerable to cyber-attacks against state and private actors" (p. 8). For the purposes of this policy paper, cyber security is not a problem that "impacts or belongs to one institution, public institutions, the private sector or citizens. It is a problem that impacts all the areas of life and society. As such, it demands necessary security measures by all users of ICT and the cyber space" (p. 19). It calls for close "cooperation with the public and private sector and cooperation with the academic world" (p. 20). For the policy paper, the private sector is also one of the "owners" of critical information infrastructure: "Due to the fact that these are not only public systems, but could also belong to the private sector, the cooperation and exchange of information with the private sector will be encouraged in order to ensure the basic security of these systems" (p. 24).

The National Security Strategy 2014-2020 classifies cyberattacks as a type one, i.e. highest importance risk. According to the Strategy, threats include "cyber attacks from state or non-state actors" (p. 25). Thus, cyber security is elevated 
to the national policy level. Albania's perspective on cyber threats has been that cyberspace is a threat to Albania's sovereignty. Hence, the elevation of cyberspace to a national security level is due to the increased risk caused by cyberattacks:

Increased communication is an added value in the economic and social development of the country, but at the same time it exposes it to the dangers of cyber nature with state and non-state actors. Cyberattacks have the potential to severely damage the exchange of information in public institutions, telecommunications and the financial and banking system, causing disruption of vital services.

Later publications of cyber security documents and strategies have been consistent in referring to the cyber threat in the national security strategy. The general public supported and did not question the decision to elevate cyber threats to the national threat level because it shared a similar perception of that threat. Given that there have been no large-scale incidents affecting critical information infrastructure in the country, Albania's inclusion of cyber threats in its national security strategy followed a preemptive logic, a fear of possible destructive cyberattacks on its critical infrastructure. Similarly, the upgrade to national threat level was not a result of any prior domestic or national threat event. Therefore, Albania's responses were influenced by events taking place in other countries, such as in Estonia, Georgia, the United Kingdom, and the United States (Guitton 2013). Albania has faced a changing security environment in which threats are increasingly interconnected and national borders are less meaningful, and this has meant Albania is no longer as distant from security threats as it once was (Burton 2013), which resonates in its framing of cyber security.

Another important national strategy regarding cyber security is the Cyber Defense Strategy 2014-2017. Uncertainty is again one of the underlying assumptions of the Strategy. According to that Strategy, "cybercriminals can use computer technology to gain access to personal data or use the Internet for exploitative or malicious purposes" (p. 5). It also states that cyberspace is a space "which anyone can use without time and geographical boundaries, asymmetrically giving advantages to malicious attackers" (p. 9).

The Cyber Defense Strategy also provides space for other actors besides the state being involved in protecting cyberspace, as it states that the efforts

to reduce cyber security threats and vulnerabilities will include concerted coordinated efforts, which should be carried out by responsible structures in the Ministry of Defense/Armed Forces, in cooperation with other government and private sectors, to identify and rehabilitate serious cyber vulnerabilities and breaches through collaborative activities.

The previous version of the Cyber Defense Strategy (2018-2020) sees uncertainty extending throughout cyberspace: "The techniques used by attackers are largely 
similar and designed to exploit the overall vulnerabilities of networks and systems" (p. 11). The Cyber Defense Strategy regards the private sector as a referent object in Albania's cyber security environment:

Regardless of the achievements in the field of systems and network protection, we must focus on the management of communications and information infrastructure as a whole, on the interconnections between networks, on the control of unauthorized access, and on the continuous control of the transmission capacity of the Ministry of Defense/Armed Forces, which are provided by public and private telecommunication companies.

Therefore, it highlights that "cyberspace is an area in which both private and public actors, civil and military, national and international, must act at the same time and be mutually dependent on one another" (p. 11).

\section{The driving influence of international obligations}

As Albania has sought to overcome shortfalls in its cyber capacity, it has worked with international organizations to mitigate the challenges posed by cyber security threats. Albania has formulated its policy around the promotion of multilateral cooperation through international institutions, particularly the Council of Europe, EU, NATO, OSCE, and the UN, and the adoption and promotion of their norms. This triangular framework (alliances, institutions, and norms) has guided Albania's cyber security policy. Obligations accepted at the national level as part of NATO and OSCE commitments have been met. With regard to the EU, which has developed one of the most comprehensive cyber security agreements of any transnational organization and argued for the establishment of specific cyber security institutions, Albania has responded positively. The EU is the main umbrella providing a comprehensive legal framework in the field, which Albania is adopting in the process of its accession to the EU (DiploFoundation 2016; EEAS 2013).

Both NATO and the EU have placed significantly more weight on a multistakeholder approach rather than on a classic state-centric approach in their cyber security policies. Albanian decision-makers have followed these cues from NATO and the EU and decreased the salience of the classic state-centric idea of sovereignty in protecting vulnerable infrastructure. This in turn increased the importance of "actor neutrality" in defining cyber security. In short, institutional structures have allowed new actors to emerge in the field - the private sector, academia, civil society, international organizations (NATO, EU) - which has caused a shift in the discussion about state sovereignty. The EU's influence in particular has increased the salience of a multi-actor approach and decreased the importance of the norm of strict classic state-based sovereignty.

The cyber security policy promoted by Albania is based on an open internet, as is highlighted by Albania signing the Council of Europe's Convention on 
Cybercrime. Albania is pursuing a path toward becoming a liberal democracy and as such does not restrict citizens' access, instead granting relatively open access to web-based materials. Nevertheless, for Albania it has been important to see that a certain type of control can be established over cyber security, with the domestic agenda being heavily influenced by the Council of Europe's Budapest Convention. The entire spectrum of cybercrimes has been criminalized by the Albanian Criminal Code, including hacking (i.e. unauthorized access); denial-ofservice attacks; phishing; infection of IT systems with malware (including ransomware, spyware, worms, Trojans and viruses); possession or use of hardware, software, or other tools used to commit cybercrime (e.g. hacking tools); identity theft or identity fraud (e.g. in connection with access devices); electronic theft (e.g. breach of confidence by a current or former employee, or criminal copyright infringement); and any other activity that adversely affects or threatens the security, confidentiality, integrity, or availability of any IT system, infrastructure, communications network, device, or data (ICLG 2018). However, countries such as Albania have weak law enforcement.

On the cyber defense side, there is a strong sense that the NATO alliance, of which Albania became a part in 2009, serves Albania's national interests very well, and that the country is also safeguarded against other influences as a result. Albania has continued to see the broader benefits of the security alliance with NATO, whose enhanced cyber assets may bring considerable benefits to its members. Albania's cyber security benefits extensively from NATO, which provides for consultation and cooperation on cyber security issues as well as for ongoing intelligence sharing. As a member of NATO, Albania signed the Memorandum of Understanding with the NATO Cyber Incident Response Centre on enhancing cyber defense in 2013. The Ministry of Defense plays a role in cyber security via the Computerization and Innovation Directorate and other institutions that are subordinate to the Ministry of Defense.

\section{The result: Networked governance}

Both the external influence of international cooperation and the public-private governance necessities that the ownership of infrastructures and capabilities entails have influenced the development of Albania's cyber security policy throughout the years. As in other countries, cyber security institutions in Albania were initially established to protect vulnerable state IT systems. Later, the target community was broadened to include other actors such as the private sector, civil society, and citizens. This occurred as institutions empowered particular actors within certain domains but also opened the potential for new actors to enter the field.

With respect to cyber security institutions in Albania, earlier-generation legislation from the period of 1992-2010 empowered mainly the state. Those laws all held the idea that cyber security was intended to protect only the state. But later, in the 2010s, new legislative acts such as the 2017 Law on Cyber Security empowered new actors to bring cyber security cases from the private sector and civil society into the governance domain for the first time. That was the start 
of the emergence of the "multi-stakeholder approach" in ensuring control over Albania's cyber security.

The 2017 Law on Cyber Security specifies that private sector operators of critical information infrastructure are obliged to implement certain required safety measures (ICLG 2018; Dushi 2016). As a result, stronger cyber security links are being formed between the Albanian government and private entities, particularly those responsible for providing critical infrastructure. The Albanian government has approved a list of operators of critical and important information infrastructure, the majority of which are private, non-public providers. These operators of critical and important information infrastructure are obliged to implement at least the minimum levels of information security requirements approved by AKCESK (the National Authority on Electronic Certification and Cyber Security), and each of these operators has a contact point responsible for cyber security. Among the most important private operators are OSHEE (electricity distribution operator); Albcontrol (air transport operator); private banks, etc.

AKCESK is responsible for overseeing the enforcement of the Law on Cyber Security and associated implementing legislation. It defines the measures to be undertaken for cyber security at the national level and is a national point of contact and assistance in case of attacks or incidents related to cyber security. The Electronic and Postal Communications Authority (AKEP) in turn regulates and monitors the establishment and operation of ICT service providers. The National Information Society Agency (AKSHI) regulates the IT sector at the national level and provides IT and electronic services to citizens, businesses, and the public administration alike.

In a separate development, the government, together with the private sector and donor agencies, established the Protik Innovation Centre in 2012 as an independent nonprofit information and communication technology center whose primary objectives include increased cooperation between the private sector, educational institutions, and the government. The Centre was established by the combined efforts of the Albanian American Development Foundation (AADF), the Government of Albania, USAID, Microsoft, Albtelecom, and CISCO.

Police authorities are responsible for enforcing the law relating to prescribed activities in cyberspace, such as various forms of cybercrime. ${ }^{1}$ Specialist units within the State Police, prosecutors' offices, and the intelligence services as well as elements of the armed forces monitor cyberspace activities that pose threats to Albanian entities and interests. The General Prosecution Office conducts criminal prosecutions against cybercrime offences through the Cybercrime Investigation Units established in eight district prosecution offices in 2014. The State Intelligence Service (SIS/SHISH), via its Cyber Crime Section, is in charge of investigating, detecting, and analyzing cybercrimes that threaten national security (Jica 2013). The Albanian Ministry of Defense has its Inter-institutional Maritime Operational Centre, whose responsibilities include civil emergencies, airspace control, and developing cyber defense capabilities (CSIS 2011).

These public and private organizations have contributed to developing situational awareness of the Albanian cyberspace as a prerequisite for prevention and 
response actions aimed at controlling some of its aspects. Private industry actors have played a crucial role in promoting cybercrime awareness, and civil society representatives have had input into the drafting of legislation, policy papers, and strategies in Albania. Taken together, the evidence suggests that private and civil society actors have played a substantial role in shaping the Albanian view of cyberspace. In this way, sovereignty has become shared with other actors, and the state has become an aggregator of domestic interests (Guarda 2015). Relevant policies have led to a more fluid conception of sovereignty, i.e. one where nonstate actors, social groups, or even individuals as well as state actors are able to materially affect the system's stability and share sovereignty.

\section{Conclusion}

As seen in the Albanian case, the state remains a central pillar in cyber security. It is mostly up to the government to decide if a particular issue constitutes a threat or not. However, other actors have increasingly found a wider remit for the selfassessment of cyber and other threats. Yet, technologically less advanced states such as Albania are less capable of preventing or terminating harmful cyber conduct and thus exercise limited control over their territorial cyber infrastructure. Therefore, they rely on other actors as well in order to alleviate cyber-specific threats.

In response to this myriad of influencing factors and actors, Albania has developed a cyber security policy that comprises various institutional elements. Functions of control are delegated to the usual organs of the state, such as the police, prosecutors, security services and the military, and to regulatory bodies such as cyber security and telecommunications regulators. Albania has aligned its cyber security policies to the view that any international policy for cyberspace should be developed using existing multi-actor governance frameworks and processes, and that a "multi-stakeholder" approach is most appropriate, which encompasses governmental, commercial, and non-governmental interests (Cornish 2015). Nontraditional actors such as the private sector, civil society, universities, and others have been networked within the Albanian cyberspace governance.

Even though Albanian legislation on cyber security defines the government as the final arbiter for cyber security cases, the private sector, civil society, and academia have also been assigned additional responsibilities for cyber security. Institutions have thus established opportunities for the unanticipated entry of new actors into the field. This dynamism accounts for shifts in the focus of cyber security and the understanding of sovereignty. In this context, Albania, like many democracies, has developed a fragmented, multi-actor system of cyber and internet regulation (Wagner 2014). The previous exclusively state-controlled governance regime has given way to a mixed governance regime of networks (Collins 2008) and to less hierarchical forms of governance (Héritier 2001), which have empowered other actors besides the state in cyber governance.

In sum, technological uncertainties and international obligations have led to the emergence of a multi-stakeholder approach in the design of laws and institutions 
in the field of cyber security and thus to a fragmentation of authority and sovereignty among different actors. Exogenous factors such as the dynamics of the cyber security sector; the threats emerging in it; and NATO, the EU, the Council of Europe, and other aspects of international institutional cooperation have encouraged the Albanian government to pursue this multi-stakeholder approach in its state planning and policies. Thus, the new legislation and institutions have provided opportunities for new actors to enter the field.

While this chapter contributes to the understanding of the implications of technological uncertainties with regard to cyber governance in states that have received little attention from the scholarly community so far, further research in other developing countries is needed to understand the relationships between uncertainties, fragmentation, and external factors driving policy development. Comparative studies can explain how multi-actor approaches can help to govern the uncertain space of new technologies.

\section{Note}

1 The Computer Crime Division at the General Directorate of the State Police was established in 2009 as part of the Albanian State Police and is Albania's primary cybercrime-combating agency. The State Police, in order to prevent and combat cybercrime, provides a software application for the online reporting of cybercrime, which is located on the official website of the Albanian State Police (Dushi and Bërdufi 2017; ICLG 2018). In 2009, a manual for investigating cybercrime and collecting computer evidence was produced for the State Police. That guide describes in detail the various types of computer evidence and how to deal with them step by step, including actions to be taken since the first moment on the scene, identification of computer evidence and its documentation, collection, packaging, transportation, and storage (Dushi and Bërdufi 2017). Complying with Article 35 of the Budapest Convention, a 24/7 point of contact was established in the Cybercrime Unit of the Albanian State Police.

\section{References}

All links checked on August 23, 2021.

Adams, J., and Albakajai, M. (2016). Cyberspace: A New Threat to the Sovereignty of the State. Management Studies, 4(6): 256-265.

Arka Telecom (2018). Armenia is Fourth in the World for Frequency of Harmful Software Attacks. Retrieved September 13, 2018, from: http://telecom.arka.am/en/news/internet/ armenia_is_fourth_in_the_world_for_frequency_of_harmful_software_attacks_/.

Bahiti, R., and Josifi, J. (2015). Towards a More Resilient Cyberspace: The Case of Albania. Information and Security, 32(2): 120-130.

Begaj, E. (2014). Albania's Vision towards Cyber Security. Paper from DCAF Young Faces 2014 - Cybersecurity Winter School for the Western Balkans. Geneva: DCAF.

Betz, D. J., and Stevens, T. (2011). Cyberspace and the State: Toward a Strategy for Cyber-Power. London: Routledge.

Brechbühl, H., Bruce, R., Dynes, S., and Johnson, M. E. (2010). Protecting Critical Information Infrastructure: Developing Cybersecurity Policy. Information Technology for Development, 16(1): 83-91. 
Bronk, C. (2008). Hacking the Nation-State: Security, Information Technology and Policies of Assurance. Information Security Journal: A Global Perspective, 17(3): 132-142.

Burton, J. (2013). Small States and Cyber Security: The Case of New Zealand. Political Science 65(2): 216-238.

Collins, R. (2008). Hierarchy to Homeostasis? Hierarchy, Markets and Networks in UK Media and Communications Governance. Media Culture and Society 30(3): 295-317.

Cornish, P. (2015). Governing Cyberspace through Constructive Ambiguity. Survival, 57(3): 153-176.

Council of Europe. (2001). Convention on Cybercrime. Strasbourg: Council of Europe.

Deibert, J., Palfrey, J., Rohozinski, R., and Zittrain, J. (2008). Access Denied: The Practice and Policy of Global Internet Filtering. Cambridge, MA: The MIT Press.

DiploFoundation. (2016). Cybersecurity in the Western Balkans: Policy Gaps and Cooperation Opportunities. Geneva: DCAF.

Dunn Cavelty, M. (2008). Cyber-Security and Threat Politics: US Efforts to Secure the Information Age. London: Routledge.

Dunn Cavelty, M. (2013). From Cyber-Bombs to Political Fallout: Threat Representations with an Impact in the Cyber-Security Discourse. International Studies Review, 15(1): $105-122$.

Dunn Cavelty, M. (2014). Breaking the Cyber-Security Dilemma: Aligning Security Needs and Removing Vulnerabilities. Science and Engineering Ethics, 20(3): 701-715.

Dunn Cavelty, M., and Egloff, F. J. (2019). The Politics of Cybersecurity: Balancing Different Roles of the State. St Antony's International Review, 15(1): 37-57.

Dunn Cavelty, M., and Jaeger, M. D. (2015). (In)visible Ghosts in the Machine and the Powers that Bind: The Relational Securitization of Anonymous. International Political Sociology, 9(2): 176-194.

Dunn Cavelty, M., and Wenger, A. (2020). Cyber Security Meets Security Politics: Complex Technology, Fragmented Politics, and Networked Science. Contemporary Security Policy, 41(1): 5-32.

Dushi, D. (2016). Cybersecurity in Albania: A Multistakeholder Approach. Paper from DCAF Young Faces 2016 - Strategic Cybersecurity Policy Development in Southeast Europe. Geneva: DCAF.

Dushi, D., and Bërdufi, N. (2017). Law Enforcement and Investigation of Cybercrime in Albania. European Scientific Journal, 13(12). Retrieved from: https://eujournal.org/ index.php/esj/article/view/9228/8769.

Egloff, F. J. (2019). Contested Public Attributions of Cyber Incidents and the Role of Academia. Contemporary Security Policy, 41(1): 55-81.

European Union External Action Service. (2013). EU Cyber Security Plan to Protect Open Internet and Online Freedom and Opportunity. Retrieved August 10, 2018, from: http:// europa.eu/rapid/press-release_IP-13-94_en.htm.

Galinec, D., Možnik, D., and Guberina, B. (2017). Cybersecurity and Cyber Defence: National Level Strategic Approach. Automatika: časopis za automatiku, mjerenje, elektroniku, računarstvo i komunikacije, 58(3): 273-286.

Gendron, A. (2013). Cyber Threats and Multiplier Effects: Canada at Risk. Canadian Foreign Policy Journal, 19(2): 178-198.

Guarda, N. (2015). Governing the Ungovernable: International Relations, Transnational Cybercrime Law, and the Post-Westphalian Regulatory State. Transnational Legal Theory 6(1): 211-249.

Guitton, C. (2013). Cyber Insecurity as a National Threat: Overreaction from Germany, France and the UK? European Security, 22(1): 21-35. 
ICLG, The International Comparative Legal Guide. (2018). Cybersecurity: A Practical Cross-Border Insight into Cybersecurity Work. London: Global Legal Group Ltd.

ITU, International Telecommunication Union. (2014). Cyberwellness Profile Albania. Geneva: ITU.

Jica, H. (2013). Cyber Security and National Security Awareness Initiatives in Albania: A Synergy Approach. Mediterranean Journal of Social Sciences, 4(10). Retrieved from: https://www.mcser.org/journal/index.php/mjss/article/view/1236/1265.

Jusufi, I. (2018). Clientelism and Informality in Albania. Eastern Journal of European Studies, 9(1): 133-150.

McAfee. (2012). Cyber-Security: The Vexed Question of Global Rules. Retrieved August 10, 2018, from: http://www.mcafee.com/us/resources/reports/rp-sda-cyber-security.pdf.

Mueller, M., Schmidt, A., and Kuerbis, B. (2013). Internet Security and Networked Governance in International Relations. International Studies Review, 15(1): 86-104.

Republic of Albania. (2014a). National Security Strategy 2014-2020. Tirana.

Republic of Albania. (2014b). Cyber Defence Strategy 2014-2017. Tirana.

Republic of Albania. (2015a). Policy Paper on Cyber Security 2015-2017. Tirana.

Republic of Albania. (2015b). Cross-Cutting Strategy 'Digital Agenda of Albania 20152020'. Tirana.

Republic of Albania. (2017). Law on Cyber Security. Tirana.

Republic of Albania. (2018a). Decision on "Approval of the List of Critical Information Infrastructures and List of Important Information Infrastructures". No. 222, 26.04.2018. Republic of Albania. (2018b). Cyber Defence Strategy 2018-2020. Tirana.

Schulzke, M. (2018). The Politics of Attributing Blame for Cyberattacks and the Costs of Uncertainty. Perspectives on Politics, 16: 954-968.

Thomas, N. (2009). Cyber Security in East Asia: Governing Anarchy. Asian Security, 5(1): $3-23$.

Wagner, B. (2014). The Politics of Internet Filtering: The United Kingdom and Germany in a Comparative Perspective. Politics, 34(1): 58-71. 